\title{
Using Restriction Fragment Length Polymorphisms to Assess Temporal Variation and Estimate the Number of Ascospores that Initiate Epidemics in Field Populations of Mycosphaerella graminicola
}

\author{
J. Zhan, C. C. Mundt, and B. A. McDonald
}

First and third authors: Institute of Plant Sciences, Phytopathology Group, ETH Zentrum/LFW, Universitätstrasse 2, CH-8092 Zürich, Switzerland; and second author: Department of Botany and Plant Pathology, 2082 Cordley Hall, Oregon State University, Corvallis 97331.

Accepted for publication 2 July 2001.

\begin{abstract}
Zhan, J., Mundt, C. C., and McDonald, B. A. 2001. Using restriction fragment length polymorphisms to assess temporal variation and estimate the number of ascospores that initiate epidemics in field populations of Mycosphaerella graminicola. Phytopathology 91:1011-1017.

Restriction fragment length polymorphisms (RFLPs) and DNA fingerprints were used to assess temporal variation and estimate the effective population size of the wheat pathogen Mycosphaerella graminicola over a 6-year period. In each year, the fungal population was founded by ascospores originating from outside the sampled fields. A total of 605 fungal isolates were included in this study. Our results indicate that the

$1 \%$ was attributed to differences among years. The lack of population differentiation among collections taken in different years indicated that the effective size of the source population was sufficiently large that genetic drift was insignificant in this location. It also suggests that the initial colonists from ascospore founder populations were a fair reflection of the source population. We estimate that the effective sizes of these field populations ranged from 3,400 to 700,000 individuals, depending on the size of the field sampled and assumptions about mutation rates. Estimates of the number of ascospores initiating epidemics of leaf blotch disease in each field plot and factors that contribute to the large effective population size of $M$. graminicola are discussed.
\end{abstract} genetic structure of these $M$. graminicola populations were stable over the 6-year period. The common alleles at each RFLP locus were present at similar frequencies each year. More than $99 \%$ of gene diversity was distributed within populations sampled from the same year and less than
Additional keywords: gene flow, genetic drift, population stability, primary inoculum, reproductive mode.
Knowledge of the possible range of temporal variation in population genetic structure is limited for many organisms (60). Empirical studies on the population genetic structure of organisms usually aim to determine the spatial distribution of genetic variation and infer the relative importance of gene flow, genetic drift, mating system, and selection in the evolutionary biology of a species. The majority of previous studies used small collections sampled from different geographic areas over several years or decades. These studies implicitly assumed that the population genetic structures of the investigated organisms were stable over the period of time covered (60). This assumption might hold true for some organisms $(16,22,44,68)$ but not for others. Plant pathologists have known for decades that populations of plant pathogen have the potential to undergo substantial shifts over short periods of time (57). Much of this information has come from annual surveys of virulence in cereal rust and mildew fungi $(2,26)$. In addition to the annual virulence surveys that cover large geographical areas, significant changes in population genetic and community structure over short periods of time have been detected in bacteria (48), fungi $(2,5,8,40)$, plants (28), and animals (20).

Though many evolutionary and demographic factors can affect temporal variation in the genetic structure of a population (61), the major forces governing this change may vary among organisms and ecosystems. These differences can be related to the ecology, biology, and life history of the studied organisms. In agricultural

Corresponding author: B. A. McDonald

E-mail address: bruce.mcdonald@ipw.agrl.ethz.ch

Publication no. P-2001-0827-01R

(C) 2001 The American Phytopathological Society ecosystems, selection due to widespread deployment of major resistance genes plays a significant role in temporal changes in populations of cereal rusts $(31,51)$ and powdery mildews $(2)$. The roles of genetic drift and migration have not been as intensively studied. Genetic drift and migration may play major roles in temporal variation of local pathogen populations (8) through the continuous extinction and recolonization of local populations that occur as a result of host dynamics (e.g., deployment of new resistance genes), chemical applications (e.g., fungicides), and changing cultural practices (e.g., burning crop stubble). During annual epidemic cycles of disease that occur in many agroecosystems, local pathogen populations can undergo annual cycles of expansion and contraction. At the end of each epidemic cycle, only a small fraction of the pathogen population successfully overseasons and serves as the founding population for the next epidemic cycle. If this numerical bottleneck is significant, the resulting genetic drift may lead to significant changes in the genetic structure of local populations from year to year.

The degree of genetic drift in a population is directly associated with its effective population size $\left(N_{e}\right) . N_{e}$ is a concept in population genetics theory that refers to the effective number of individuals that contribute sexual progeny to the next generation (49). Populations with large effective size tend to be stable over time because the effect from random drift is limited. Effective population size also is related to other evolutionary processes such as gene flow and mutation. Though it may play an important role in evolution, effective population size is seldom estimated in natural populations. This is because $N_{e}$ is extremely difficult to estimate accurately (24) and it is sensitive to the level of population subdivision and the geographic scale from which the population is sampled $(11,62)$. 
Mycosphaerella graminicola (Fuckel) J. Schröt. in Cohn (anamorph Septoria tritici Roberge in Desmaz.) is a heterothallic ascomycete (25) that causes Septoria tritici leaf blotch on wheat and other graminaceous grasses (7). This pathogenic fungus is distributed worldwide and has received increased attention since Septoria tritici leaf blotch has become more economically important (15). The increased importance of the disease coincides with the widespread use of early maturing semidwarf wheat cultivars that are susceptible to the pathogen (3).

The infective organs of the fungus are haploid ascospores and pycnidiospores. Ascospores produced by the teleomorph can be found on wheat stubble (50), as well as on growing wheat plants $(23,25,66)$. The ascospores are dispersed by wind (27) and are the major source of inoculum leading to initiation of Septoria tritici leaf blotch epidemics in wheat fields (52-54). Pycnidiospores produced by the anamorph are disseminated by rain-splash and are thought to cause the majority of secondary infections during the growing season $(12,55)$, though ascospores may also make significant contributions to secondary cycles of infection $(12,66,67)$.

M. graminicola has been the subject of population genetic studies for more than a decade $(10,33,34,38,66,67)$. Population genetic analysis based on DNA fingerprints and single-locus restriction fragment length polymorphism (RFLP) markers provided evidence that sexual reproduction played an important role in the population structure of $M$. graminicola $(10,66)$ and in the epidemiology of the disease $(66,67)$. These studies also indicated that genetic variation was high in this fungus $(33,34)$ and that the majority of this genetic variation was distributed on a small spatial scale (33). The high similarity in allele frequencies among fungal populations collected worldwide suggests that long-distance gene flow has occurred during the recent evolutionary history of the pathogen $(6,39)$. Though a previous experiment showed that the genetic structure of $M$. graminicola populations was stable over a 3 -year period (9), it is unclear if the observed stability would be maintained over a longer period of time. It also is unclear what the effective population sizes are for these populations and how effective population size relates to the primary inoculum of leaf blotch disease. Therefore, the objectives of this study were to (i) determine whether the genetic structure of $M$. graminicola populations changed over a 6-year period; (ii) estimate $N_{e}$ and determine its contribution to the stability of these $M$. graminicola populations; and (iii) use $N_{e}$ to infer the number of ascospores initiating an epidemic in our experimental field plots.

\section{MATERIALS AND METHODS}

Source of fungal isolates. The fungal isolates were collected from the Oregon State University Botany and Plant Pathology Field Laboratory at Corvallis, during the winter/spring of 1990, 1991, 1992, and 1995. During the 1990 to 1992 seasons, four winter wheat cultivars (Gene, Madsen, Malcolm, and Stephens) that differed in resistance to $M$. graminicola were planted in pure stands and in all possible two-, three-, and four-way mixtures (15 treatments total) in a randomized complete block design (RCBD) with three replications. Individual plots were $1.5 \mathrm{~m}$ wide and $6.1 \mathrm{~m}$ long. The field used to obtain isolates in 1990 was not planted with known hosts of $M$. graminicola in the previous

TABLE 1. Genotype diversities, their standard errors and the percentage of the theoretical maximum obtained for four Mycosphaerella graminicola collections made from Oregon in 1990, 1991, 1992, and 1995a

\begin{tabular}{lcccc}
\hline Populations & 1990 & 1991 & 1992 & 1995 \\
\hline $\begin{array}{l}\text { Genotype diversity } \\
(\hat{G})\end{array}$ & $\begin{array}{c}335 \pm 15.03 \\
(406)\end{array}$ & $\begin{array}{c}50 \pm 2.57 \\
(52)\end{array}$ & $\begin{array}{c}50 \pm 3.34 \\
(54)\end{array}$ & $\begin{array}{c}45 \pm 0.00 \\
(45)\end{array}$ \\
$\begin{array}{c}\text { Percentage of } \\
\text { theoretical maximum }\end{array}$ & 83 & 96 & 93 & 100 \\
\hline
\end{tabular}

${ }^{a}$ The sample size for each population is in parentheses.
3 years. The same field was used for the 1991 and 1992 collections. At the end of each growing season, grain was harvested and stubble was left in the field to decay naturally. Several weeks before the next crop was planted, the wheat stubble was buried in the soil with a disk and a rototiller (9). Through this process, the pycnidiospores present on this stubble would decay (21) and not be able to act as primary inoculum for the next crop. In 1995, two wheat cultivars (Madsen and Stephens) were planted in pure stands and in 1:1 mixtures in an RCBD with four replications (66). The size of individual plots in this year was $3.3 \mathrm{~m}$ wide and $5.3 \mathrm{~m}$ long. The field used in this experiment was different, but close to the one used in the 1990 to 1992 experiments. This field also was not planted with known hosts of $M$. graminicola in the previous several years.

In 1990, wheat leaves infected with M. graminicola were sampled from all field plots twice over the course of the growing season. The first sample was made midway through the growing season (6 March), and the second sample was made near the end of the growing season (30 May). In 1991 and 1992, infected leaves were collected near the end of the growing season (6 June) from six plots distributed throughout the field. In 1995, collections were made from three plots at an early stage of the growing season (10 February). In each year, 20 infected leaves were chosen randomly along two parallel transects running the length of each plot. Each leaf was collected from a different plant or tiller.

The infected leaf tissue was air dried at room temperature for 2 weeks before isolations were made. One single-spore isolate of M. graminicola was made from each infected leaf that expressed a viable cirrhus. A total of 605 isolates assayed for RFLPs and DNA fingerprints were included in this analysis. Among these isolates, 444 were from 1990, 58 each were from 1991 and 1992, and 45 were from 1995.

DNA extraction, restriction digestion, Southern blotting, and hybridization. Total DNA from each isolate was extracted using a cetyltrimethylammonium bromide (CTAB) extraction protocol described previously (34). The concentrations of the DNA suspensions were measured with a DNA fluorometer (Hoefer TKO 100; Hoefer Pharmacia Biotech, San Francisco). Five micrograms of DNA from each isolate was digested with the restriction enzyme PstI. The DNA fragments were separated by electrophoresis on $0.8 \%$ agarose Tris-borate-EDTA gels and were transferred to a nylon membrane by alkaline capillary transfer. Afterward, the membranes were dried and stored in sealed plastic bags until needed. Seven anonymous RFLP probes (pSTS192, pSTS2, pSTS197, pSTL53, pSTS14, pSTL10, and pSTL70) chosen from a $M$. graminicola genomic library $(34,35)$ were hybridized in sequence to the Southern blots. Probe $p S T L 70$ was a DNA fingerprinting probe that hybridized to a moderately repetitive DNA sequence dispersed across several chromosomes (35). The remaining six probes hybridized to seven RFLP loci distributed across seven chromosomes (pSTS192 hybridizes to two unlinked loci) (36). The probes were radioactively labeled with $\mathrm{dCT}^{32} \mathrm{P}$ through nick translation. The labeled probes were hybridized to

TABLE 2. The mean number of alleles for seven restriction fragment length polymorphism (RFLP) loci in four Mycosphaerella graminicola collections made from Oregon, in 1990, 1991, 1992, and 1995

\begin{tabular}{lcccc}
\hline RFLP loci & $\begin{array}{c}1990 \\
(N=406)\end{array}$ & $\begin{array}{c}1991 \\
(N=52)\end{array}$ & $\begin{array}{c}1992 \\
(N=54)\end{array}$ & $\begin{array}{c}1995 \\
(N=45)\end{array}$ \\
\hline$p S T S 192 A-P s t \mathrm{I}$ & 8 & 3 & 3 & 2 \\
$p S T S 192 B-P s t \mathrm{I}$ & 4 & 1 & 4 & 1 \\
$p S T S 14-P s t \mathrm{I}$ & 4 & 2 & 2 & 2 \\
$p S T S 2-P s t \mathrm{I}$ & 11 & 6 & 7 & 4 \\
$p S T L 10-P s t \mathrm{I}$ & 14 & 4 & 4 & 6 \\
$p S T L 53-P s t \mathrm{I}$ & 11 & 5 & 5 & 9 \\
$p S T S 197-P s t \mathrm{I}$ & 9 & 5 & 4 & 3 \\
Mean & 8.7 & 3.6 & 4.1 & 3.9 \\
\hline
\end{tabular}

a The sample sizes $(N)$ for these collections are indicated in parentheses. 
the membranes overnight at $60^{\circ} \mathrm{C}$ in a hybridization incubator. Following hybridization, the membranes were washed and exposed to X-ray film at $-80^{\circ} \mathrm{C}$. The radioactive probes were stripped off the membranes after the films had been developed. Hybridization was continued until all isolates had been probed with the pSTL70 DNA fingerprint probe and the six singlelocus probes.

Data analyses. Each probe $\times$ enzyme combination was treated as a different RFLP locus. DNA fragments or combinations of fragments with different sizes were treated as alleles at each RFLP locus. Only alleles that could be scored unambiguously and isolates that had complete data were included in this analysis. Isolates with the same DNA fingerprint and multilocus haplotype were treated as individual members of the same clone (36). Allele frequencies for each collection were calculated by using only one representative from each genotype. These clone-corrected allele frequencies were used to calculate gene diversity and estimate the magnitude of population subdivision.

Fungal collections made from different cultivars in the same year were very similar for allele frequency (37) and were treated as a single population. Genetic variation in the fungal collections was measured by gene diversity (43) and genotype diversity (58). Hierarchical analysis (43) was used to partition gene diversity into two levels according to year: variation within years and among years. The allele frequencies in different collections were compared with a contingency chi-square test (13). For this comparison, alleles with frequencies lower than 0.05 in all four collections were combined into a single category. Nei's measures of genetic distance (42) and population differentiation (43) were used to estimate the level of population subdivision among years. The expected number of new alleles emerging from mutation in each population, $\theta$ ( $=2 N_{e} u$ for haploid organisms, where $N_{e}$ is the effective population size and $u$ is the mutation rate of the investigated locus), was estimated with the method described by Ewens (14). Assuming an infinite allele model and constant mutation rates, the average number of alleles $(k)$ detected in a sample would be

$$
\sum_{j} \frac{\theta}{\theta+j-1}
$$

$(j=1,2,3, \ldots \ldots n$, where $n$ is the sample size) if the locus studied is selectively neutral $(14,32)$. The $\theta$ for each population was calculated twice. The first calculation used all isolates in each clonecorrected collection. The second calculation used a randomly drawn subsample of 40 isolates from each of the four collections. The 40 isolates in the 1990 collection were sampled from six plots (covering the same total land area as the 1991 and 1992 plots) that were randomly chosen from the total of 45 plots. This resampling procedure was repeated 100 times. $\theta$ s of the four populations were estimated yearly and their means were calculated over the 100 subsamples. Because $\theta$ is a direct function of the effective population size and the effective size of a population is positively correlated with the geographic area over which the population is

TABLE 3. The expected number of new alleles emerging from mutation in each population, $\theta\left(=2 N_{e} u\right)(14)$ for the seven restriction fragment length polymorphism loci in the four Mycosphaerella graminicola collections made from Oregon in 1990, 1991, 1992, and 1995

\begin{tabular}{lllll}
\hline Populations & 1990 & 1991 & 1992 & 1995 \\
\hline$p S T S 192 A-P s t \mathrm{I}$ & 1.66 & 0.82 & 0.50 & 0.26 \\
pSTS192B-PstI & 0.50 & 0.00 & 0.80 & 0.00 \\
$p S T S 14-P s t \mathrm{I}$ & 0.50 & 0.24 & 0.24 & 0.26 \\
$p S T S 2-P s t \mathrm{I}$ & 1.92 & 1.52 & 1.50 & 0.56 \\
$p S T L 10-P s t \mathrm{I}$ & 2.44 & 0.82 & 0.80 & 1.72 \\
$p S T L 53-P s t \mathrm{I}$ & 1.92 & 1.52 & 1.14 & 3.46 \\
$p S T S 197-P s t \mathrm{I}$ & 1.48 & 0.82 & 0.80 & 0.56 \\
Mean $^{\mathrm{a}}$ & 1.42 & 0.68 & 0.82 & 0.80 \\
\hline
\end{tabular}

${ }^{\mathrm{a}}$ Estimated from the mean number of alleles found at a locus. sampled $(11,62)$, this bootstrapping procedure allowed us to compare $\theta$ s of populations collected from different total land areas.

\section{RESULTS}

A total of 511 distinct genotypes were detected among the 548 isolates with complete data. The most common genotype was observed four times, four genotypes were found three times, 24 genotypes were found twice, and the remaining genotypes were detected only once. Isolates with the same genotypes were sampled from the same field plots. No identical genotypes were found among the fungal collections made from different years. Stoddart and Taylor's (58) measurement of genotype diversity ranged from 83 to $100 \%$ of its theoretical maximum (Table 1). A significant difference in genotype diversity was detected only between the 1990 and 1995 collections.

The average number of alleles per RFLP locus ranged from 3.6 in the 1991 collection to 8.7 in the 1990 collection (Table 2). There were fewer rare alleles at each locus in the 1991, 1992, and 1995 collections than in the 1990 collection. $\theta$ ranged from 0.00 for locus pSTS192B-PstI to 3.46 for locus pSTL53-PstI (Table 3). The collection made in 1990 had a higher $\theta$ than collections from other years. However, after the effect of differences in field area sampled was removed by bootstrapping, no significant differences in resampled $\theta \mathrm{s}$ and the expected number of alleles (Fig. 1) were found among the collections.

For most RFLP loci, one or two alleles were present at a high frequency (Table 4). In the collection from 1990, most of the alleles were present at frequencies lower than 0.02 . There were no significant differences in allele frequencies for any RFLP locus among the collections (Table 4). On average, over 99\% of the total gene diversity was present within the collections sampled from the same year. Less than $1 \%$ of total gene diversity was attributed to population differentiation across years. The average genetic distances between any pair of the collections ranged from 0.00 to 0.02 (Table 5).

\section{DISCUSSION}

The main objectives of our study were to determine the degree of temporal variation in genetic structure of Oregon M. graminicola

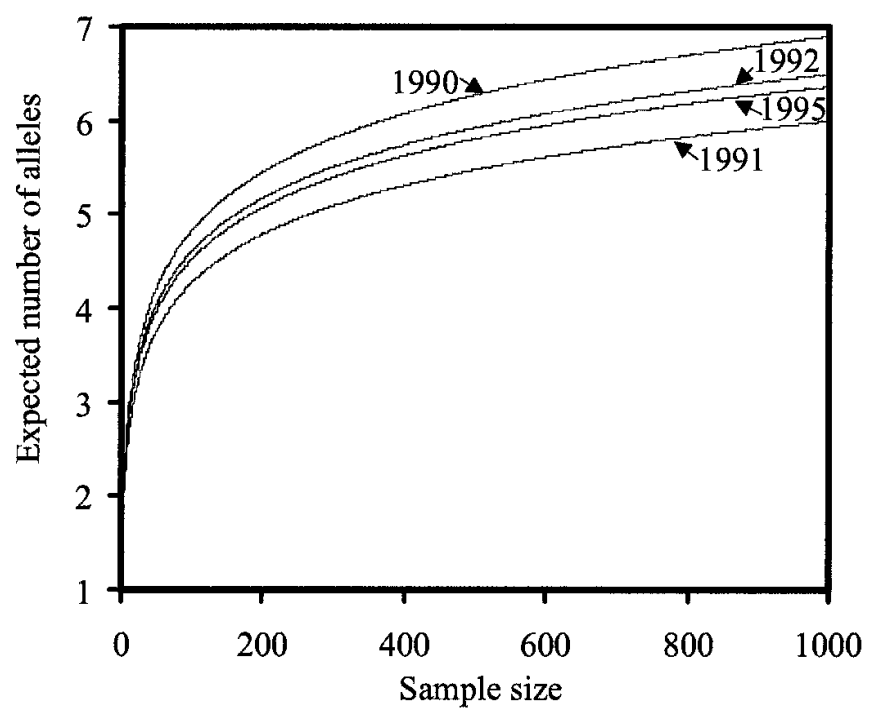

Fig. 1. The expected number of alleles as a function of the sample size in Oregon populations of Mycosphaerella graminicola in 1990, 1991, 1992, and 1995. Values for $\theta$ based on resampling for each of the four populations were $0.89,0.76,0.83$, and 0.79 , respectively. The procedure used to estimate $\theta$ based on resampling populations is described in the text. 
populations and to infer the effective sizes of these populations. We achieved these objectives by comparing allele frequencies across seven RFLP loci among collections that were sampled from the same geographic location over a 6-year period, representing a potential for at least 30 generations of asexual reproduction and a minimum of six cycles of sexual reproduction. Zhan (65) showed that weather conditions could support six generations of asexual reproduction for M. graminicola during a 4-month period in 1995 in this location. Our results support the previous finding (9) that the genetic structure of the $M$. graminicola population exhibited a high degree of stability over years. We did not detect any significant differences in allele frequencies for seven RFLP loci among the fungal collections sampled from different years. Though the total gene diversity was high, the majority of this genetic diversity (more than 99\%) was distributed within a collection sampled from a single year. Only a small amount of the total gene diversity (less than $1 \%$ on average across all seven loci) was attributed to the population differentiation among years.

The fungal collection sampled from 1990 had a higher average number of alleles per locus than the other three collections (Table 2 ). We believe that this was due to differences in sample size. In 1990, 444 isolates were included in the RFLP analysis compared with 58 each in 1991 and 1992 and 45 in 1995 . With a sample size of 444 , we have a probability $>95 \%$ to include all alleles present at a frequency higher than 0.01, assuming that the RFLP markers

TABLE 4. Allele frequencies for seven restriction fragment length polymorphism (RFLP) loci in four Mycosphaerella graminicola collections made from Oregon in 1990,1991, 1992, and 1995

\begin{tabular}{|c|c|c|c|c|c|c|}
\hline \multirow[b]{2}{*}{ RFLP locus } & \multirow[b]{2}{*}{ Allele } & \multicolumn{4}{|c|}{ Populations } & \multirow[b]{2}{*}{$\chi^{2}$} \\
\hline & & 1990 & 1991 & 1992 & 1995 & \\
\hline pSTS192-PstIA & $\begin{array}{l}1 \\
2 \\
p \\
N\end{array}$ & $\begin{array}{l}0.94 \\
0.03 \\
0.03 \\
401\end{array}$ & $\begin{array}{c}0.88 \\
0.08 \\
0.04 \\
57\end{array}$ & $\begin{array}{c}0.91 \\
0.05 \\
0.04 \\
56\end{array}$ & $\begin{array}{c}0.95 \\
0.05 \\
0.00 \\
43\end{array}$ & $6.36(6)$ \\
\hline pSTS192-PstIB & $\begin{array}{l}1 \\
p \\
N\end{array}$ & $\begin{array}{l}0.98 \\
0.02 \\
406\end{array}$ & $\begin{array}{c}1.00 \\
0.00 \\
56\end{array}$ & $\begin{array}{c}0.98 \\
0.02 \\
56\end{array}$ & $\begin{array}{c}1.00 \\
0.00 \\
44\end{array}$ & $1.99(3)$ \\
\hline pSTS14-PstI & $\begin{array}{l}1 \\
2 \\
\mathrm{p} \\
N\end{array}$ & $\begin{array}{l}0.81 \\
0.18 \\
0.01 \\
407\end{array}$ & $\begin{array}{c}0.82 \\
0.18 \\
0.00 \\
57\end{array}$ & $\begin{array}{c}0.82 \\
0.18 \\
0.00 \\
56\end{array}$ & $\begin{array}{c}0.82 \\
0.18 \\
0.00 \\
44\end{array}$ & $0.85(6)$ \\
\hline$p S T S 2-P s t \mathrm{I}$ & $\begin{array}{l}1 \\
2 \\
3 \\
p \\
N\end{array}$ & $\begin{array}{l}0.65 \\
0.08 \\
0.20 \\
0.07 \\
400\end{array}$ & $\begin{array}{c}0.67 \\
0.06 \\
0.20 \\
0.07 \\
54\end{array}$ & $\begin{array}{c}0.57 \\
0.13 \\
0.21 \\
0.09 \\
56\end{array}$ & $\begin{array}{c}0.82 \\
0.02 \\
0.14 \\
0.02 \\
44\end{array}$ & $8.87(9)$ \\
\hline pSTL10-PstI & $\begin{array}{l}1 \\
2 \\
3 \\
p \\
N\end{array}$ & $\begin{array}{l}0.68 \\
0.05 \\
0.22 \\
0.05 \\
409\end{array}$ & $\begin{array}{c}0.65 \\
0.05 \\
0.28 \\
0.02 \\
57\end{array}$ & $\begin{array}{c}0.52 \\
0.10 \\
0.36 \\
0.02 \\
56\end{array}$ & $\begin{array}{c}0.64 \\
0.00 \\
0.29 \\
0.07 \\
43\end{array}$ & $14.51(9)$ \\
\hline pSTL53-PstI & $\begin{array}{l}1 \\
2 \\
3 \\
5 \\
6 \\
7 \\
p \\
N\end{array}$ & $\begin{array}{l}0.48 \\
0.11 \\
0.16 \\
0.04 \\
0.12 \\
0.03 \\
0.06 \\
404\end{array}$ & $\begin{array}{c}0.56 \\
0.07 \\
0.16 \\
0.05 \\
0.14 \\
0.00 \\
0.02 \\
57\end{array}$ & $\begin{array}{c}0.53 \\
0.11 \\
0.23 \\
0.00 \\
0.11 \\
0.00 \\
0.02 \\
56\end{array}$ & $\begin{array}{c}0.46 \\
0.02 \\
0.07 \\
0.05 \\
0.21 \\
0.05 \\
0.14 \\
43\end{array}$ & $26.86(18)$ \\
\hline pSTS197-PstI & $\begin{array}{l}1 \\
2 \\
3 \\
p \\
N\end{array}$ & $\begin{array}{l}0.63 \\
0.23 \\
0.11 \\
0.03 \\
259\end{array}$ & $\begin{array}{c}0.64 \\
0.18 \\
0.16 \\
0.02 \\
57\end{array}$ & $\begin{array}{c}0.59 \\
0.28 \\
0.11 \\
0.02 \\
56\end{array}$ & $\begin{array}{c}0.59 \\
0.36 \\
0.05 \\
0.00 \\
44\end{array}$ & $9.65(9)$ \\
\hline
\end{tabular}

a Alleles with frequencies less than 0.05 in all four collections were pooled into one category (allele " $p ")$. Sample sizes $(N)$ used to calculate allele frequencies are shown for each locus. The chi-square values and their degrees of freedom (in parentheses) for measurement of population differentiation are also included. we used are neutral (37) and that allele frequencies in these fungal populations followed a multinominal distribution. However, with sample sizes of 58 or 45 , the probability to detect alleles present at a frequency higher than 0.01 decreases dramatically to 44 or $36 \%$, respectively. This explanation is consistent with the finding that many of the alleles detected in the 1990 collection were present at low frequencies. The difference in the number of alleles among collections might also reflect differences in the total geographic area over which the fungal collections were made. In 1990, the fungal collection was made from an area totaling $412 \mathrm{~m}^{2}$ compared with $55 \mathrm{~m}^{2}$ each in 1991 and 1992 and $52 \mathrm{~m}^{2}$ in 1995. Ingvarsson and Olsson (24) and Whitlock and Barton (62) demonstrated previously that the effective size of a population is positively associated with the geographic area over which the population was sampled. Populations sampled from larger geographic areas tend to have larger effective population sizes, and consequently, a higher number of alleles are observed. After the effects due to sample size and geographical area were corrected by resampling, the difference in the average number of alleles per locus was not significantly different among collections (Fig. 1).

Each year, the field population of $M$. graminicola included in our analysis was founded by a sample of the local population represented in ascospore showers. During the course of our field experiments, we took several steps to prevent the carry over of fungal populations from the previous year. These steps included the selection of field plots that were not planted previously with wheat and its related species for several years prior to our experiments and the destruction of crop debris that could harbor $S$. tritici pycnidia present in previous wheat crops in these fields. The finding that no identical genotypes were shared among collections from different years and our observations that the disease symptoms were uniformly distributed throughout the experimental plots from early in the season suggest that we successfully eliminated the pycnidia of previous years. The lack of population differentiation among these samples across years indicates that the effective size of the indigenous (source) population was sufficiently large enough that random drift made a trivial contribution to its genetic structure. It also suggests that the founder population each year was large and diverse enough that its genetic structure was a fair reflection of the source population. Assuming mutation rates of $10^{-4}$ to $10^{-6}$ for our RFLP loci, we estimate that the effective sizes of these field populations ranged from 3,400 to 420,000 , respectively, in 1991, 1992, and 1995 and from 7,000 to 700,000, respectively, in 1990. After taking into account the field area sampled for these collections, we estimate that effective population sizes ranged from 3,800 to 4,400 (based on resampling $\theta$ s and a mutation rate of $10^{-4}$ ) in field plots covering an area of $55 \mathrm{~m}^{2}$ or approximately $70 \mathrm{M}$. graminicola strains per square meter. We consider it likely that the effective size in the local source population of this fungus will be far higher than these numbers. It has been demonstrated (56) that in a population consisting of $n$ patches, the effective size of the population is $n$ times the effective population size of a patch, assuming the migration rate between the patches is high and that each patch has equal effective population size. During the growing season there were many other wheat fields (patches) present in the Willamette Valley, approximately $100 \mathrm{~km}$ from the region where our collections were made, and we hypothesize that a high level of gene flow probably occurred among these field populations of M. graminicola (6).

Our estimates of $N_{e}$ vary greatly depending on the mutation rates at these RFLP loci. We do not have exhaustive data on mutation rates at these RFLP loci in $M$. graminicola, but we believe that these rates are likely to be lower than $10^{-4}$ based on our available data. In a field experiment reported previously (65), we introduced $10 \mathrm{M}$. graminicola strains into experimental plots to initiate an epidemic of Septoria tritici leaf blotch. Seven months later, and following at least six generations of in planta asexual reproduction, we recovered approximately 400 asexual progeny of 
the 10 inoculated strains and assayed them for nine RFLP loci. We did not find any mutant RFLP alleles within clones among the nine loci in the 400 asexual progeny, suggesting that the mutation rate across these RFLP loci was less than 1 out of 3,600 over six generations or less than $\approx 5 \times 10^{-5}$ per generation.

Only spores that successfully establish infections contribute to the effective size of a pathogen population (41), and all of the primary infections by $M$. graminicola in our system were derived from sexual ascospores. We believe that our estimate of effective population size, in this case, reflects the number of ascospores that successfully infected and colonized the area of wheat sampled in each year and contributed to the gene pool of the next generations. Nunney (46) pointed out that the effective size of a random mating population usually was close to one-half the number of individuals involved in sexual reproduction. We estimate that between several thousand and several hundred thousand (depending on mutation rates and field sizes) ascospores initiated infections during each growing season.

Our estimates of effective population size are consistent with the large number of genotypes, based on DNA fingerprints found in these field collections. For example, we found 371 distinct genotypes among the 406 isolates having complete data in the samples collected from 1990. These genotypes were taken from a very small portion of the infected leaves present in this field. Mundt (unpublished data) observed that, when infections from fall ascospore showers are first expressed, there are approximately 300 plants per square meter of wheat field in the Willamette Valley and that each plant has at least one lesion. Our previous results (39) indicate that the majority of isolates sampled from different leaves have different DNA fingerprints (hence different genotypes) and many isolates sampled from the same leaf had different DNA fingerprints. Linde and McDonald (30) collected and analyzed 40 isolates from each of five lesions in a Swiss wheat field and found that each lesion was composed of between two and five different genotypes. Given these findings, we believe that the actual number of genotypes present in wheat fields would be at least twice the number of infected leaves or at least several hundred thousand genotypes.

In contrast to $N$, the actual number of individuals in the population $(45,46)$, the effective size of a population is directly related to many other factors that influence the variation of reproductive success among individuals $(1,63)$. One of these factors is the mating system of a species $(29,64)$. Inbreeding with close relatives tends to reduce the effective size of a population (64) because the reproductive success of individuals is no longer dependent on the two independent alleles per locus (47). A second factor associated with the effective size of a population is the dispersal mechanism of the organism. Organisms with capability for long-distance dispersal tend to have larger effective population sizes because long-distance dispersal decreases the chance that related individuals will meet and mate (17). The level of gene flow among populations also will affect the effective size of a population (4). The spatial distribution of many organisms is fragmented, with patches of suitable habitat separated by large areas of unsuitable habitat (1). High gene flow links these fragmented populations together, therefore, increasing their effective population size (56). M. graminicola is characterized by sexual reproduction year round $(23,25,54,66)$. Sexual recombination provides a mechanism to generate a large number of genotypes and, thus, increases the potential effective population size. In addition, the potential for long-distance dispersal of ascospores (50) and significant gene flow among populations (6) might also contribute to the large effective population sizes found in this pathogen.

The number of spores of primary inoculum that initiate a plant disease epidemic is an important parameter to consider in plant pathology, especially in the field of epidemiology. Historically, this parameter has been estimated by spore trapping $(18,59)$ or by counting lesions. Spore trapping data only indicates the number of spores present in the air above a field at a given time. It does not indicate how many of these spores successfully contact, infect, colonize, and reproduce on the plants. The accuracy of lesion counts is affected by timing, lesion density, latent period, and symptomology. The measure of effective population size that we propose here is based on neutral genetic markers and population genetics theory and takes into account the number of genetically distinct individuals that successfully infect and reproduce and transmit their genes to subsequent generations following the initial infection. We believe that this method offers an alternative and complementary measure of the effective inoculum that initiates and sustains an epidemic. We recognize that the methods we present here are relatively crude and that these estimates are constrained by some assumptions. For example, the genetic markers should be selectively neutral and mutation rates often are not known. Prior knowledge of the population genetics and evolutionary biology of the studied organisms may not be available, making the data more difficult to interpret. Because the effective population size of an organism can vary from generation to generation (19), it would be optimum to conduct this type of study by making collections directly following the initiation of the epidemic. In our case, some of the fungal collections were sampled from the later stages of the epidemic, and hence these estimates of $N_{e}$ include immigrants that arrived after the first ascospore shower. We do not believe this significantly alters our estimate of the number of ascospores initiating epidemics of Septoria tritici leaf blotch because we found similar effective sizes for fungal population sampled from different seasons of a same year (J. Zhan and B. A. McDonald, unpublished data) as well as for different years (Fig. 1). Our evidence suggests that a large number of immigrant ascospores (at least 70 per square meter) initiated the epidemics in our experimental plots.

TABLE 5. Nei's measures of gene diversity, population subdivision, and genetic distance for seven restriction fragment length polymorphism (RFLP) loci in four Mycosphaerella graminicola collections made from Oregon in 1990, 1991, 1992, and 1995

\begin{tabular}{|c|c|c|c|c|c|c|c|c|c|c|c|c|}
\hline \multirow[b]{2}{*}{ RFLP loci } & \multicolumn{4}{|c|}{$H_{i}^{\mathrm{a}}$} & \multirow[b]{2}{*}{$H_{T}^{\mathrm{b}}$} & \multirow[b]{2}{*}{$G_{\mathrm{st}}{ }^{\mathrm{c}}$} & \multicolumn{6}{|c|}{$D^{\mathrm{d}}$} \\
\hline & 1990 & 1991 & 1992 & 1995 & & & $1990-91$ & $1990-92$ & $1990-95$ & $1991-92$ & $1991-95$ & $1992-95$ \\
\hline pSTS192A-PstI & 0.11 & 0.22 & 0.17 & 0.09 & 0.13 & 0.01 & 0.00 & 0.00 & 0.00 & 0.00 & 0.00 & 0.00 \\
\hline pSTS192B-PstI & 0.04 & 0.00 & 0.10 & 0.00 & 0.04 & 0.01 & 0.00 & 0.00 & 0.00 & 0.00 & 0.00 & 0.00 \\
\hline pSTS14-PstI & 0.31 & 0.29 & 0.29 & 0.30 & 0.31 & 0.00 & 0.00 & 0.00 & 0.00 & 0.00 & 0.00 & 0.00 \\
\hline$p S T S 2-P s t \mathrm{I}$ & 0.53 & 0.51 & 0.61 & 0.32 & 0.52 & 0.01 & 0.00 & 0.01 & 0.01 & 0.01 & 0.01 & 0.03 \\
\hline pSTL10-PstI & 0.49 & 0.50 & 0.59 & 0.53 & 0.51 & 0.01 & 0.00 & 0.05 & 0.01 & 0.02 & 0.00 & 0.03 \\
\hline pSTL53-PstI & 0.72 & 0.63 & 0.64 & 0.72 & 0.70 & 0.01 & 0.01 & 0.01 & 0.06 & 0.02 & 0.05 & 0.09 \\
\hline pSTS197-PstI & 0.54 & 0.52 & 0.56 & 0.52 & 0.54 & 0.01 & 0.01 & 0.01 & 0.03 & 0.02 & 0.06 & 0.01 \\
\hline Pooled & 0.39 & 0.38 & 0.42 & 0.35 & 0.39 & 0.01 & 0.00 & 0.01 & 0.02 & 0.01 & 0.01 & 0.02 \\
\hline
\end{tabular}

${ }^{a}$ Gene diversity for each population.

${ }^{\mathrm{b}}$ Combined gene diversity across all populations.

c Population differentiation.

${ }^{\mathrm{d}}$ Genetic distance. 


\section{ACKNOWLEDGMENTS}

This project was supported by the National Science Foundation grant DEB-9306377 and Texas Agricultural Experiment Station project $\mathrm{H}-$ 6928. We thank R.-S. Chen for the 1990 to 1992 data set and M. Hoffer for her contribution to the field aspects of this project.

\section{LITERATURE CITED}

1. Amos, W., and Harwood, J. 1998. Factors affecting levels of genetic diversity in natural populations. Phil. Trans. R. Soc. Lond. B. 353:177186.

2. Andrivon, D., and DeVallavieille-Pope, C. 1993. Racial diversity and complexity in regional populations of Erisyphe graminis f. sp. hordei in France over a 5-year period. Plant Pathol. 42:443-464.

3. Baltazar, B. M., Scahren, A. L., and Kronstad, W. E. 1990. Association between dwarfing genes 'Rht1' and 'Rht2' and resistance to Septoria tritici blotch in winter wheat (Triticum aestivum L. em Thell). Theor. Appl. Genet. 79:422-426.

4. Barton, N. H., and Whitlock, M. C. 1997. The evolution of metapopulations. Pages 183-210 in: Metapopulation Dynamics: Ecology, Genetics and Evolution. I. Hanski and M. Gilpin, eds. Academic Press, San Diego, CA.

5. Bayman, P., and Cotty, P. J. 1991. Vegetative compatibility and genetic diversity in the Aspergillus flavus population of a single field. Can. J. Bot. 69:1707-1711.

6. Boeger, J. M., Chen, R. S., and McDonald, B. A. 1993. Gene flow between geographic populations of Mycosphaerella graminicola (anamorph Septoria tritici) detected with restriction fragment length polymorphism markers. Phytopathology 83:1148-1154.

7. Brokenshire, T. 1975. The role of graminaceous species in the epidemiology of Septoria tritici on wheat. Plant Pathol. 24:33-38.

8. Burdon, J. J., and Jarosz, A. M. 1992. Temporal variation in the racial structure of flax rust (Melampsora lini) populations growing on natural stands of wild flax (Linum marginale): Local versus metapopulation dynamics. Plant Pathol. 41:165-179.

9. Chen, R. S., Boeger, J. M., and McDonald, B. A. 1994. Genetic stability in a population of a plant pathogenic fungus over time. Mol. Ecol. 3:209-218.

10. Chen, R. S., and McDonald, B. A. 1996. Sexual reproduction plays a major role in the genetic structure of populations of the fungus Mycosphaerella graminicola. Genetics 142:1119-1127.

11. Chesser, R. K., Rhodes, O. E., Sugg, D. W., and Schnabel, A. 1993. Effective sizes for subdivided populations. Genetics 135:1221-1232.

12. Eriksen, L., Shaw, M. W., and Østergård, H. 2001. A model of the effect of pseudothecia on genetic recombination and epidemic development in populations of Mycosphaerella graminicola. Phytopathology 91:240248.

13. Everitt, B. S. 1977. The Analysis of Contingency Tables. Wiley-Interscience, New York.

14. Ewens, W. J. 1972. The sampling theory of selectively neutral alleles. Theor. Popul. Biol. 3:87-112.

15. Eyal, Z. 1981. Integrated control of Septoria diseases of wheat. Plant Dis. 65:763-768.

16. Garant, D., Dodson, J. J., and Bernatchez, L. 2000. Ecological determinants and temporal stability of the within-river population structure in Atlantic salmon (Salmo salar L.). Mol. Ecol. 9:615-628.

17. Gilbert, D. A., Lehman, A., Pusey, A. E., Stephens, J. C., and O'Brien, S. J. 1991. Analytical DNA fingerprinting in lions: Parentage, genetic diversity and kinship. J. Hered. 82:378-386.

18. Gutierrez, W. A., and Shew, H. D. 1998. Identification and quantification of ascospores as the primary inoculum for collar rot of greenhouseproduced tobacco seedlings. Plant Dis. 82:485-490.

19. Hartl, D. L., and Clark, A. G. 1997. Principles of Population Genetics. Sinauer Associates, Sunderland, MA.

20. Hedgecock, D. 1994. Temporal and spatial genetic-structure of marine animal populations in the California current. Calif. Coop. Ocean. Fish. 35:73-81.

21. Hilu, H. M., and Bever, W. M. 1957. Inoculation, oversummering, and suscept-pathogen relationship of Septoria tritici on Triticum species. Phytopathology 47:474-480.

22. Hossaert-McKey, M., Valero, M., Magda, D., Jarry, M., Cuguen, J., and Vernet, P. 1996. The evolving genetic history of a population of Lathyrus sylvestris: Evidence from temporal and spatial genetic structure. Evolution 50:1808-1821.

23. Hunter, T., Coker, R. R., and Royle, D. J. 1999. The teleomorph stage, Mycosphaerella graminicola, in epidemics of septoria tritici blotch on winter wheat in the UK. Plant Pathol. 48:51-57.

24. Ingvarsson, P. K., and Olsson, K. 1997. Hierarchical genetic structure and effective population sizes in Phalacrus substriatus. Heredity 79:153161.

25. Kema, G. H. J., Verstappen, E. C. P., Todorova, M., and Waalwijk, C. 1996. Successful crosses and molecular tetrad and progeny analysis demonstrate heterothallism in Mycosphaerella graminicola. Curr. Genet. 30:252-258.

26. Kolmer, J. A. 1989. Virulence and race dynamics of Puccinia recondita f. sp. tritici in Canada during 1956-1987. Phytopathology 79:349-356.

27. Leath, S., Scharen, A. L., Lund, R. E., and Dietz-Holmes, M. E. 1993. Factors associated with global occurrences of Septoria nodorum blotch and Septoria tritici blotch of wheat. Plant Dis. 77:1266-1270.

28. Levy, F., and Neal, C. L. 1999. Spatial and temporal genetic structure in chloroplast and allozyme markers in Phacelia dubia implicate genetic drift. Heredity 82:422-431.

29. Li, C. C. 1955. Population Genetics. University of Chicago Press, Chicago.

30. Linde, C., and McDonald, B. A. 2000. Spatial distribution of Mycosphaerella graminicola genotypes within leaf blotch lesions on wheat. (Abstr.) Phytopathology 90(suppl.):S47.

31. Martens, J. W., McKenzie, R. I. H., and Green, G. J. 1970. Gene-forgene relationships in the Avena Puccinia graminis host-parasite system in Canada. Can. J. Bot. 48:969-975.

32. McDermott, J. M., McDonald, B. A., Allard, R. W., and Webster, R. K. 1989. Genetic variability for pathogenicity, isozyme, ribosomal DNA and colony color variants in populations of Rhynchosporium secalis. Genetics 122:561-565.

33. McDonald, B. A., and Martinez, J. P. 1990. DNA restriction fragment length polymorphisms among Mycosphaerella graminicola (anamorph Septoria tritici) isolates collected from a single wheat field. Phytopathology 80:1368-1373.

34. McDonald, B. A., and Martinez, J. P. 1990. Restriction fragment length polymorphisms in Septoria tritici occur at a high frequency. Curr. Genet. $17: 133-138$.

35. McDonald, B. A., and Martinez, J. P. 1991. DNA fingerprinting of the plant pathogenic fungus Mycosphaerella graminicola (anamorph Septoria tritici). Exp. Mycol. 15:146-158.

36. McDonald, B. A., and Martinez, J. P. 1991. Chromosome length polymorphisms in a Septoria tritici population. Curr. Genet. 19:265-271.

37. McDonald, B. A., Mundt, C. C., and Chen, R. S. 1996. The role of selection on the genetic structure of pathogen populations: Evidence from field experiments with Mycosphaerella graminicola on wheat. Euphytica 92:73-86

38. McDonald, B. A., Pettway, R. E., Chen, R. S., Boeger, J. M., and Martinez, J. P. 1995. The population genetics of Septoria tritici (teleomorph Mycosphaerella graminicola). Can. J. Bot. 73(suppl.):S292-S301.

39. McDonald, B. A., Zhan, J., Yarden, O., Hogan, K., Garton, J., and Pettway, R. E. 1999. The population genetics of Mycosphaerella graminicola and Phaeosphaeria nodorum. Pages 44-69 in: Septoria on Cereals: A Study of Pathosystems. J. A. Lucas, P. Bowyer, and H. M. Anderson, eds. CAB International, Wallingford, UK.

40. Miller, J. S., Hamm, P. B., and Johnson, D. A. 1997. Characterization of the Phytophthora infestans population in the Columbia Basin of Oregon and Washington from 1992 to 1995. Phytopathology 87:656-660.

41. Mundt, C. C. 1990. Disease dynamics in agroecosystems. Pages 263-299 in: Agroecology. C. R. Carroll, J. H. Vandermeer, and P. M. Rossett, eds. McGraw-Hill Publishing, New York.

42. Nei, M. 1972. Genetic distance between populations. Am. Nat. 106:283292.

43. Nei, M. 1973. Analysis of gene diversity in subdivided populations. Proc. Natl. Acad. Sci. USA 70:3321-3323.

44. Nielsen, E. E., Hansen, M. M., and Loeschcke, V. 1999. Genetic variation in time and space: Microsatellite analysis of extinct and extant populations of Atlantic salmon. Evolution 53:263-268

45. Nunney, L. 1993. The influence of mating system and overlapping generations on effective population size. Evolution 47:1329-1341.

46. Nunney, L. 1995. Measuring the ratio of effective population size and adult numbers using genetic and ecological data. Evolution 49:389-392.

47. Nunney, L. 1999. The effective size of a hierarchically structured population. Evolution 53:1-10.

48. Pernthaler, J., Glockner, F. O., Unterholzner, S., Alfreider, A., Psenner, R., and Amann, R. 1998. Seasonal community and population dynamics of pelagic bacteria and archaea in a high mountain lake. Appl. Environ. Microbiol. 64:4299-4306.

49. Russell, P. J. 1996. Genetics. HarperCollins College Publishers Inc., New York

50. Sanderson, F. R. 1972. Mycosphaerella graminicola (Fuckel) Sanderson comb. nov., the ascogenous state of Septoria tritici Rob. and Desm. N. Z. J. Bot. 14:359-360.

51. Schafer, J. F., and Long, D. L. 1988. Relations of races and virulences of Puccinia recondita $\mathrm{f}$. $\mathrm{sp}$. tritici to wheat cultivars and areas. Plant Dis. 
72:25-27.

52. Schuh, W. 1990. Influence of tillage systems on disease intensity and spatial pattern of Septoria leaf blotch. Phytopathology 80:1337-1340.

53. Shaw, M. W., and Royle, D. J. 1987. Spatial distributions of Septoria nodorum and Septoria tritici within crops of winter wheat. Plant Pathol. 36:84-94.

54. Shaw, M. W., and Royle, D. J. 1989. Airborne inoculum as a major source of Septoria tritici (Mycosphaerella graminicola) infections in winter wheat crops in the UK. Plant Pathol. 38:35-43.

55. Shaw, M. W., and Royle, D. J. 1993. Factors determining the severity of epidemics of Mycosphaerella graminicola (Septoria tritici) on winter wheat in the UK. Plant Pathol. 42:882-899.

56. Slatkin, M., and Voelm, L. 1991. Fst in a hierarchical island model. Genetics 127:627-629.

57. Stakman, E. C. 1957. Problems in preventing plant disease epidemics. Am. J. Bot. 44:259-267.

58. Stoddart, J. A., and Taylor, J. F. 1988. Genotypic diversity: Estimation and prediction in samples. Genetics 118:705-711.

59. Sutton, D. K., MacHardy, W. E., and Lord, W. G. 2000. Effects of shredding or treating apple leaf litter with urea on ascospore dose of Venturia inaequalis and disease buildup. Plant Dis. 84:1319-1326.

60. Tessier, N., and Bernatchez, L. 1999. Stability of population structure and genetic diversity across generations assessed by microsatellites among sympatric populations of landlocked Atlantic salmon (Salmo salar L.). Mol. Ecol. 6:169-179.

61. Whitlock, M. C. 1992. Temporal fluctuations in demographic parameters and the genetic variance among populations. Evolution 46:608-615.

62. Whitlock, M. C., and Barton, N. H. 1997. The effective size of a subdivided population. Genetics 146:427-441.

63. Wright, S. 1938. Size of population and breeding structure in relation to evolution. Science 87:430-431.

64. Wright, S. 1943. Isolation by distance. Genetics 28:114-138.

65. Zhan, J. 1998. The role of immigration, mating system and selection on the genetic structure of populations of the wheat pathogen Mycosphaerella graminicola. Ph.D. diss. A\&M University, Texas.

66. Zhan, J., Mundt, C. C., and McDonald, B. A. 1998. Measuring immigration and sexual reproduction in field populations of Mycosphaerella graminicola. Phytopathology 88:1330-1337.

67. Zhan, J., Mundt, C. C., and McDonald, B. A. 2000. Estimation of rates of recombination and migration in populations of plant pathogens-A reply. Phytopathology 90:324-326.

68. Ziemke, F., Brettar, I., and Hofle, M. G. 1997. Stability and diversity of the genetic structure of a Shewanella putrefaciens population in the water column of the central Baltic. Aquat. Microbiol. Ecol. 13:63-74. 